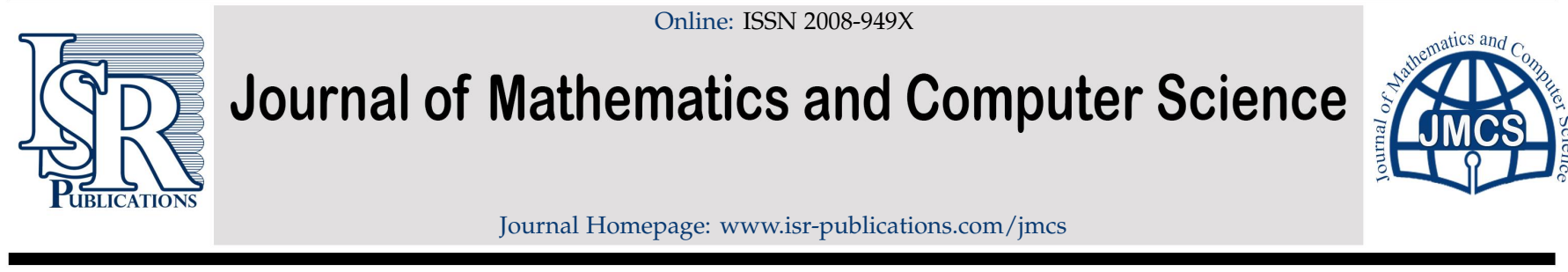

\title{
Almost bi-quasi-interior ideals and fuzzy almost bi-quasi- interior ideals of semigroups
}

\author{
Ronnason Chinrama ${ }^{a}$, Warud Nakkhasen ${ }^{b, *}$ \\ a Division of Computational Science, Faculty of Science, Prince of Songkla University, Hat Yai, Songkhla 90110, Thailand. \\ ${ }^{b}$ Department of Mathematics, Faculty of Science, Mahasarakham University, Maha Sarakham 44150, Thailand.
}

\begin{abstract}
The notion of bi-quasi-interior ideals of semigroups was introduced by Rao in 2018 which is a generalization of left ideals, right ideals, bi-ideals, quasi-ideals, interior ideals, bi-interior ideals and bi-quasi ideals of semigroups. In this paper, we introduce the concept of almost bi-quasi-interior ideals as a generalization of bi-quasi-interior ideals of semigroups and investigate their properties. Moreover, we define the notion of fuzzy almost bi-quasi-interior ideals of semigroups and consider some connection between almost bi-quasi-interior ideals and fuzzy almost bi-quasi-interior ideals of semigroups.
\end{abstract}

Keywords: Bi-quasi-interior ideal, almost bi-quasi-interior ideal, fuzzy almost bi-quasi-interior ideal.

2020 MSC: 03E72, $20 \mathrm{M} 12$.

(C)2022 All rights reserved.

\section{Introduction and Preliminaries}

In 1980, Grosek and Satko [3] introduced the concepts of left, right, and two-sided almost ideals of semigroups. A nonempty subset $A$ of a semigroup $S$ is called a left almost ideal of $S$ if $x A \cap A \neq \emptyset$ for all $x \in S$. A right almost ideal of a semigroup $S$ is defined similarly. A nonempty subset $A$ of a semigroup $S$ is called an almost ideal of $S$ if $x A \cap A \neq \emptyset$ and $A y \cap A \neq \emptyset$ for all $x, y \in S$. They studied the characterization of these ideals when a semigroup contains no proper left, right, two-sided ideals. Later in 1981, Bogdanović [1] introduced the notion of almost bi-ideals in semigroups as a generalization of bi-ideals. Now in 2018, Wattanatripop et. al [24] suggested the concept of quasi-almost-ideals by using the concept of almost ideals and quasi-ideals of semigroups. Recently, Kaopusek et. al [5] introduced the notions almost interior ideals and weakly almost interior ideals of semigroups by using the concepts of almost ideals and interior ideals of semigroups and investigated their properties. Moreover, the concept of various types of almost ideals has been studied in other algebraic structures (see, e.g., [7, 9, 11, 15, 17-23]).

The concept of fuzzy subsets was introduced by Zadeh [25] as a function from a nonempty set $X$ to the unit interval $[0,1]$. In mathematics, the fuzzy subset is a mathematical extension of classical sets. Rosenfeld [16] developed the fuzzy subsets to describe the concept of fuzzy subgroups of groups, which provided

\footnotetext{
*Corresponding author

Email addresses: ronnason.c@psu.ac.th (Ronnason Chinram), warud.n@msu.ac.th (Warud Nakkhasen)

doi: $10.22436 /$ jmcs.026.02.03
}

Received: 2021-06-21 Revised: 2021-08-13 Accepted: 2021-08-26 
as the inspiration for a variety of algebraic structures. Then, Kuroki [8] was the first to consider the use of fuzzy subsets in semigroups. Furthermore, many researchers have discussed on the generalizations of the concepts of fuzzy subsets with applications in algebraic structures (see, e.g., $[2,4,10])$. For any two fuzzy subsets $f$ and $g$ of a nonempty set $X, f \subseteq g$ if and only if $f(x) \leqslant g(x)$ for all $x \in X$.

The intersection and the union of two fuzzy subsets $f$ and $g$ of a nonempty set $X$, denoted by $f \cap g$ and $f \cup g$, respectively, are defined by letting $x \in X$,

$$
(f \cap g)(x)=\min \{f(x), g(x)\}, \quad \text { and } \quad(f \cup g)(x)=\max \{f(x), g(x)\} .
$$

For a fuzzy subset $f$ of a nonempty set $X$, the support of $f$ is defined by

$$
\operatorname{supp}(f):=\{x \in X \mid f(x) \neq 0\} .
$$

Let $A$ be a nonempty subset of $X$. The characteristic mapping $C_{A}$ of $A$ is a fuzzy subset of $X$ defined by for every $x \in X$,

$$
C_{A}(x)= \begin{cases}1 & \text { if } x \in A \\ 0 & \text { otherwise }\end{cases}
$$

Lemma 1.1 ([9]). Let $\mathrm{A}$ and $\mathrm{B}$ be nonempty subsets of a nonempty set $\mathrm{X}$ and let $\mathrm{f}$ and $\mathrm{g}$ be fuzzy subsets of $\mathrm{X}$. Then the following statements hold:

(i) $\mathrm{C}_{\mathrm{A} \cap \mathrm{B}}=\mathrm{C}_{\mathrm{A}} \cap \mathrm{C}_{\mathrm{B}}$;

(ii) $\mathrm{A} \subseteq \mathrm{B}$ if and only if $\mathrm{C}_{\mathrm{A}} \subseteq \mathrm{C}_{\mathrm{B}}$;

(iii) $\operatorname{supp}\left(C_{A}\right)=A$;

(iv) if $\mathrm{f} \subseteq \mathrm{g}$, then $\operatorname{supp}(\mathrm{f}) \subseteq \operatorname{supp}(\mathrm{g})$.

$\mathrm{Pu}$ and $\mathrm{Liu}$ [13] gave a definition for fuzzy points. For any element $x$ of $X$ and $\alpha \in(0,1]$, a fuzzy point $x_{\alpha}$ of $X$ defined by for each $y \in X$,

$$
x_{\alpha}(y)= \begin{cases}\alpha & \text { if } y=x, \\ 0 & \text { otherwise. }\end{cases}
$$

Let $f$ and $g$ be fuzzy subsets of a semigroup $S$. A product $f \circ g$ is defined by for every $x \in S$,

$$
(f \circ g)(x)= \begin{cases}\sup _{x=y z}[\min \{f(y), g(z)\}], & \text { if } \exists y, z \in S \text { such that } x=y z, \\ 0, & \text { otherwise. }\end{cases}
$$

Lemma 1.2 ([9]). If $A$ and $B$ are subsets of a semigroup $S$, then $C_{A} \circ C_{B}=C_{A B}$.

The concept of bi-quasi-interior ideals of semigroups was introduced by Rao [14] in 2018 as a generalization of left ideals, right ideals, quasi-ideals, bi-ideals, interior ideals, bi-interior ideals and bi-quasi ideals in semigroups.

Definition 1.3 ([14]). A nonempty subset B of a semigroup $S$ is called a bi-quasi-interior ideal of $S$ if $B$ is a subsemigroup of $\mathrm{S}$ and $\mathrm{BSBSB} \subseteq \mathrm{B}$.

In this paper, as a further generalization of different types of ideals in semigroups, we introduce the notion of almost bi-quasi-interior ideals as a generalization of bi-quasi-interior ideals of semigroups and investigate some their properties. Moreover, we define the notion of fuzzy almost bi-quasi-interior ideals of semigroups and give some connection between almost bi-quasi-interior ideals and fuzzy almost bi-quasi-interior ideals of semigroups. 


\section{Almost bi-quasi-interior ideals of semigroups}

In this section, we introduce the concept of almost bi-quasi-interior ideals of semigroups as a generalization of bi-quasi-interior ideals of semigroups and give some properties of them.

Definition 2.1. A nonempty subset $B$ of a semigroup $S$ is called an almost bi-quasi-interior ideal of $S$ if $(\mathrm{B} x \mathrm{~B} y \mathrm{~B}) \cap \mathrm{B} \neq \emptyset$ for all $x, y \in S$.

We note that every bi-quasi-interior ideal of a semigroup is an almost bi-quasi-interior ideal. In general, an almost bi-quasi-interior ideals of a semigroup need not to be a bi-quasi-interior ideal as shown by the following examples.

Example 2.2. Let $S=\{a, b, c, d, e\}$. Define a binary operation · on $S$ by the following table:

\begin{tabular}{c|ccccc}
$\cdot$ & $a$ & $b$ & $c$ & $d$ & $e$ \\
\hline$a$ & $a$ & $d$ & $a$ & $d$ & $d$ \\
$b$ & $a$ & $b$ & $a$ & $d$ & $d$ \\
$c$ & $a$ & $d$ & $c$ & $d$ & $e$ \\
$d$ & $a$ & $d$ & $a$ & $d$ & $d$ \\
$e$ & $a$ & $d$ & $c$ & $d$ & $e$
\end{tabular}

Then, $(S, \cdot)$ is a semigroup [6]. Let $B=\{a, b\}$. By routine calculations, we obtain that $B$ is an almost bi-quasi-interior ideal of $S$, but $B$ is not a bi-quasi-interior ideal of $S$ because $B S B S B=\{a, b, d\} \nsubseteq B$.

Example 2.3. Consider $S=\{a, b, c\}$ with the following multiplication table:

\begin{tabular}{c|ccc}
$\cdot$ & $a$ & $b$ & $c$ \\
\hline$a$ & $a$ & $b$ & $c$ \\
$b$ & $b$ & $b$ & $c$ \\
$c$ & $b$ & $b$ & $c$
\end{tabular}

Then, $(S, \cdot)$ is a semigroup [12]. By routine computations, we have that $\{a, c\}$ is an almost bi-quasi-interior ideal of $S$, but $\{a, c\}$ is not a bi-quasi-interior ideal of $S$ because $\{a, c\} S\{a, c\} S\{a, c\}=S \nsubseteq\{a, c\}$.

Next, we investigate some properties of almost bi-quasi-interior ideals of semigroups.

Theorem 2.4. Let $\mathrm{B}$ be an almost bi-quasi-interior ideal of a semigroup $\mathrm{S}$. If $\mathrm{A}$ is a subset of $\mathrm{S}$ containing $\mathrm{B}$, then $A$ is also an almost bi-quasi-interior ideal of $S$.

Proof. Assume that $A$ is a subset of $S$ such that $B \subseteq A$. Let $x, y \in S$. Then,

$$
\emptyset \neq(\mathrm{B} x \mathrm{~B} y \mathrm{~B}) \cap \mathrm{B} \subseteq(\mathrm{A} x \mathrm{~A} y \mathrm{~A}) \cap \mathrm{A} .
$$

It turns out that $(A x A y A) \cap A \neq \emptyset$. Thus, $A$ is an almost bi-quasi-interior ideal of $S$.

Corollary 2.5. If $\mathrm{A}$ and $\mathrm{B}$ are almost bi-quasi-interior ideals of a semigroup $\mathrm{S}$, then $\mathrm{A} \cup \mathrm{B}$ is also an almost bi-quasi-interior ideal of $\mathrm{S}$.

Proof. The proof follows by Theorem 2.4 .

In the following example, we present that the intersection of any two almost bi-quasi-interior ideals of a semigroup $S$ need not to be an almost bi-quasi-interior ideal of $S$.

Example 2.6. Consider $S=\{a, b, c\}$ together with the multiplication $\cdot$ on $S$ defined in Example 2.3, and then $\{a, c\}$ is an almost bi-quasi-interior ideal of $S$. In addition, we can show that $\{a, b\}$ is an almost biquasi-interior ideal of $S$. However, $\{a, b\} \cap\{a, c\}=\{a\}$ is not an almost bi-quasi-interior ideal of $S$ because $(\{a\} c\{a\} b\{a\}) \cap\{a\}=\emptyset$. 
Theorem 2.7. Let $S$ be a semigroup and $|S|>2$. Then $S$ has no proper almost bi-quasi-interior ideals if and only if for every $a \in S$ there exist $x_{a}, y_{a} \in S$ such that $(S \backslash\{a\}) x_{a}(S \backslash\{a\}) y_{a}(S \backslash\{a\})=\{a\}$.

Proof. Assume that $S$ has no proper almost bi-quasi-interior ideals and let $a \in S$. Then, $S \backslash\{a\}$ is not an almost bi-quasi-interior ideal of $S$. It follows that there exist $x_{a}, y_{a} \in S$ such that

$$
\left[\left(S \backslash\{a\} x_{a}(S \backslash\{a\}) y_{a}(S \backslash\{a\})\right] \cap(S \backslash\{a\})=\emptyset .\right.
$$

Thus,

$$
\left[\left(S \backslash\{a\} x_{a}(S \backslash\{a\}) y_{a}(S \backslash\{a\})\right] \subseteq S \backslash(S \backslash\{a\})=\{a\} .\right.
$$

This implies that $(S \backslash\{a\}) x_{a}(S \backslash\{a\}) y_{a}(S \backslash\{a\})=\{a\}$.

Conversely, suppose that $S$ contains a proper almost bi-quasi-interior ideal. Let I be a proper almost bi-quasi-interior ideal of $S$. Thus, there exists $a \in S$ such that $a \notin I$. By assumption, there exist $x_{a}, y_{a} \in S$ such that $(S \backslash\{a\}) x_{a}(S \backslash\{a\}) y_{a}(S \backslash\{a\})=\{a\}$. Since $I \subseteq S \backslash\{a\}$ and by Theorem 2.4, we have that $S \backslash\{a\}$ is an almost bi-quasi-interior ideal of $S$. It follows that

$$
\emptyset=\{a\} \cap(S \backslash\{a\})=\left[(S \backslash\{a\}) x_{a}(S \backslash\{a\}) y_{a}(S \backslash\{a\})\right] \cap(S \backslash\{a\}) \neq \emptyset .
$$

This is a contradiction. Therefore, $S$ has no proper almost bi-quasi-interior ideals.

\section{Fuzzy almost bi-quasi-interior ideals of semigroups}

In this section, we introduce the concept of fuzzy almost bi-quasi-interior ideals of semigroups and discuss the connections between almost bi-quasi-interior ideals and their fuzzification in semigroups.

Definition 3.1. Let $f$ be a fuzzy subset of a semigroup $S$ such that $f \neq 0$. Then $f$ is called a fuzzy almost bi-quasi-interior ideal of $S$ if for every fuzzy points $x_{\alpha}$ and $y_{\beta}$ of $S,\left(f \circ x_{\alpha} \circ f \circ y_{\beta} \circ f\right) \cap f \neq 0$.

Theorem 3.2. Let $\mathrm{f}$ be a fuzzy almost bi-quasi-interior ideal of a semigroup $\mathrm{S}$. If $\mathrm{g}$ is a fuzzy subset of $\mathrm{S}$ such that $\mathrm{f} \subseteq \mathrm{g}$, then $\mathrm{g}$ is a fuzzy almost bi-quasi-interior ideal of $\mathrm{S}$.

Proof. Assume that $g$ is a fuzzy subset of $S$ such that $f \subseteq g$. Then, for every fuzzy points $x_{\alpha}$ and $y_{\beta}$ of $S$, we have that $\left(f \circ x_{\alpha} \circ f \circ y_{\beta} \circ f\right) \cap f \neq 0$. It follows that $\left(f \circ x_{\alpha} \circ f \circ y_{\beta} \circ f\right) \cap f \subseteq\left(g \circ x_{\alpha} \circ g \circ y_{\beta} \circ g\right) \cap g$. We obtain that $\left(g \circ x_{\alpha} \circ g \circ y_{\beta} \circ g\right) \cap g \neq 0$. Hence, $g$ is a fuzzy almost bi-quasi-interior ideal of $S$.

The following results can be achieved by Theorem 3.2.

Corollary 3.3. Let $\mathrm{f}$ and $\mathrm{g}$ be fuzzy almost bi-quasi-interior ideals of a semigroup $\mathrm{S}$. Then $\mathrm{f} \cup \mathrm{g}$ is also a fuzzy almost bi-quasi-interior ideal of $\mathrm{S}$.

Example 3.4. Consider $S=\{a, b, c\}$ together with the binary operation - on $S$ defined in Example 2.3. Define fuzzy subsets $f$ and $g$ of $S$ by for every $x \in S$,

$$
f(x)=\left\{\begin{array}{ll}
0.9 & \text { if } x=b, \\
0 & \text { otherwise, }
\end{array} \text { and } g(x)= \begin{cases}0.3 & \text { if } x=c \\
0 & \text { otherwise }\end{cases}\right.
$$

We can see that for every fuzzy points $x_{\alpha}$ and $y_{\beta}$ of $S$,

$$
\left[\left(f \circ x_{\alpha} \circ f \circ y_{\beta} \circ f\right) \cap f\right](b) \neq 0, \quad \text { and }\left[\left(g \circ x_{\alpha} \circ g \circ y_{\beta} \circ g\right) \cap g\right](c) \neq 0 .
$$

This means that $f$ and $g$ are fuzzy almost bi-quasi-interior ideals of $S$. Moreover, $f \cap g$ is not a fuzzy almost bi-quasi-interior ideal of $S$ because $f \cap g=0$.

By Example 3.4, we have that the intersection of any two fuzzy almost bi-quasi-interior ideals of a semigroup $\mathrm{S}$ need not to be a fuzzy almost bi-quasi-interior ideal of $\mathrm{S}$. 
Theorem 3.5. Let $\mathrm{B}$ be a nonempty subset of a semigroup $\mathrm{S}$. Then $\mathrm{B}$ is an almost bi-quasi-interior ideal of $\mathrm{S}$ if and only if $\mathrm{C}_{\mathrm{B}}$ is a fuzzy almost bi-quasi-interior ideal of $\mathrm{S}$.

Proof. Assume that $B$ is an almost bi-quasi-interior ideal of $S$. Let $x, y \in S$ and $\alpha, \beta \in(0,1]$. Then, $(B \times B y B) \cap B \neq \emptyset$. Thus, there exists $a \in S$ such that $a \in B \times B y B$ and $a \in B$. So, $a=b_{1} \times b_{2} y b_{3}$ for some $b_{1}, b_{2}, b_{3} \in B$. It turns out that

$$
\left(C_{B} \circ x_{\alpha} \circ C_{B} \circ y_{\beta} \circ C_{B}\right)(a)=\sup _{a=b_{1} x b_{2} y b_{3}}\left[\min \left\{C_{B}\left(b_{1}\right), x_{\alpha}(x), C_{B}\left(b_{2}\right), y_{\beta}(y), C_{B}\left(b_{3}\right)\right\}\right] \neq 0,
$$

and $C_{B}(a)=1$. This implies that $\left(C_{B} \circ x_{\alpha} \circ C_{B} \circ y_{\beta} \circ C_{B}\right) \cap C_{B} \neq 0$. Therefore, $C_{B}$ is a fuzzy almost bi-quasi-interior ideal of $S$.

Conversely, assume that $C_{B}$ is a fuzzy almost bi-quasi-interior ideal of $S$. Let $x, y \in S$ and $\alpha, \beta \in(0,1]$. Then, $\left(C_{B} \circ x_{\alpha} \circ C_{B} \circ y_{\beta} \circ C_{B}\right) \cap C_{B} \neq 0$. Thus, there exists $a \in S$ such that $\left(C_{B} \circ x_{\alpha} \circ C_{B} \circ y_{\beta} \circ C_{B}\right)(a) \neq 0$ and $C_{B}(a) \neq 0$. This means that $a \in B \times B y B$ and $a \in B$, and so $(B x B y B) \cap B \neq \emptyset$. Consequently, $B$ is an almost bi-quasi-interior ideal of $S$.

Theorem 3.6. Let $\mathrm{f}$ be a fuzzy subset of a semigroup $\mathrm{S}$. Then $\mathrm{f}$ is a fuzzy almost bi-quasi-interior ideal of $\mathrm{S}$ if and only if $\operatorname{supp}(f)$ is an almost bi-quasi-interior ideal of $\mathrm{S}$.

Proof. Assume that $f$ is a fuzzy almost bi-quasi-interior ideal of $S$. Let $x, y \in S$ and $\alpha, \beta \in(0,1]$. Then, $\left(f \circ x_{\alpha} \circ f \circ y_{\beta} \circ f\right) \cap f \neq 0$. Thus, there exists $a \in S$ such that $\left(f \circ x_{\alpha} \circ f \circ y_{\beta} \circ f\right)(a) \neq 0$ and $f(a) \neq 0$. Also, there exist $b, c, d \in S$ such that $a=b x c y d$ and

$$
\sup _{a=b x c y d}\left[\min \left\{f(b), x_{\alpha}(x), f(c), y_{\beta}(y), f(d)\right\}\right]=\left(f \circ x_{\alpha} \circ f \circ y_{\beta} \circ f\right)(a) \neq 0 .
$$

So, $f(b) \neq 0, f(c) \neq 0$ and $f(d) \neq 0$. Hence, $a, b, c, d \in \operatorname{supp}(f)$. It follows that

$$
\left(C_{\operatorname{supp}(f)} \circ x_{\alpha} \circ C_{\operatorname{supp}(f)} \circ y_{\beta} \circ C_{\operatorname{supp}(f)}\right)(a) \neq 0,
$$

and $C_{\operatorname{supp}(f)}(a) \neq 0$. This means that $\left(C_{\operatorname{supp}(f)} \circ x_{\alpha} \circ C_{\operatorname{supp}(f)} \circ y_{\beta} \circ C_{\operatorname{supp}(f)}\right) \cap C_{\operatorname{supp}(f)} \neq 0$. We obtain that $\mathrm{C}_{\text {supp ( } f)}$ is a fuzzy almost bi-quasi-interior ideal of $S$. By Theorem 3.5, we get that $\operatorname{supp}(f)$ is an almost bi-quasi-interior ideal of $\mathrm{S}$.

Conversely, assume that $\operatorname{supp}(f)$ is an almost bi-quasi-interior ideal of $\mathrm{S}$. By Theorem $3.5, \mathrm{C}_{\operatorname{supp}(f)}$ is a fuzzy almost bi-quasi-interior ideal of $S$. Thus, for every fuzzy points $x_{\alpha}$ and $y_{\beta}$ of $S$, we have that $\left(C_{\operatorname{supp}(f)} \circ x_{\alpha} \circ C_{\operatorname{supp}(f)} \circ y_{\beta} \circ C_{\operatorname{supp}(f)}\right) \cap C_{\operatorname{supp}(f)} \neq 0$. So, there exists $a \in S$ such that

$$
\left(C_{\operatorname{supp}(f)} \circ x_{\alpha} \circ C_{\operatorname{supp}(f)} \circ y_{\beta} \circ C_{\operatorname{supp}(f)}\right)(a) \neq 0,
$$

and $C_{\operatorname{supp}(f)}(a) \neq 0$. That is, there exist $b, c, d \in S$ such that $a=b x c y d$ and

$$
\sup _{a=b x c y d}\left[\min \left\{C_{\operatorname{supp}(f)}(b), x_{\alpha}(x), C_{\operatorname{supp}(f)}(c), y_{\beta}(y), C_{\operatorname{supp}(f)}(d)\right\}\right] \neq 0 .
$$

This implies that $C_{\text {supp (f) }}(b) \neq 0, C_{\text {supp }(f)}(c) \neq 0$ and $C_{\text {supp }(f)}(d) \neq 0$. We obtain that $f(a) \neq 0, f(b) \neq 0$, $f(c) \neq 0$, and $f(d) \neq 0$. Hence, $\left(f \circ x_{\alpha} \circ f \circ y_{\beta} \circ f\right)(a)=\sup _{a=b x c y d}\left[\min \left\{f(b), x_{\alpha}(x), f(c), y_{\beta}(y), f(d)\right\}\right] \neq 0$. It follows that $\left(f \circ x_{\alpha} \circ f \circ y_{\beta} \circ f\right) \cap f \neq 0$ for all fuzzy points $x_{\alpha}$ and $y_{\beta}$ of $S$. Consequently, $f$ is a fuzzy almost bi-quasi-interior ideal of $S$.

Next, we define minimal fuzzy almost bi-quasi-interior ideals in semigroups and investigate some the connection between minimal almost bi-quasi-interior ideals and minimal fuzzy almost bi-quasi-interior ideals of semigroups.

Definition 3.7. Let $S$ be a semigroup. A fuzzy almost bi-quasi-interior ideal $f$ of $S$ is called minimal if for any fuzzy almost bi-quasi-interior ideal $g$ of $S$ such that $g \subseteq f$, we get $\operatorname{supp}(f)=\operatorname{supp}(g)$. 
Theorem 3.8. Let $\mathrm{B}$ be a nonempty subset of a semigroup $\mathrm{S}$. Then $\mathrm{B}$ is a minimal almost bi-quasi-interior ideal of $\mathrm{S}$ if and only if $\mathrm{C}_{\mathrm{B}}$ is a minimal fuzzy almost bi-quasi-interior ideal of $\mathrm{S}$.

Proof. Assume that $B$ is a minimal almost bi-quasi-interior ideal of $S$. By Theorem $3.5, C_{B}$ is a fuzzy almost bi-quasi-interior ideal of $S$. Let $g$ be any fuzzy almost bi-quasi-interior ideal of $S$ such that $g \subseteq C_{B}$. By Lemma 1.1, $\operatorname{supp}(\mathrm{g}) \subseteq \operatorname{supp}\left(\mathrm{C}_{\mathrm{B}}\right)=$ B. Also, $\operatorname{supp}(\mathrm{g})$ is an almost bi-quasi-interior ideal of $S$ by Theorem 3.6. By given assumption, we have that $\operatorname{supp}(g)=B=\operatorname{supp}\left(C_{B}\right)$. Therefore, $C_{B}$ is a minimal fuzzy almost bi-quasi-interior ideal of $S$.

Conversely, assume that $C_{B}$ is a minimal fuzzy almost bi-quasi-interior ideal of $S$. Then, $B$ is an almost bi-quasi-interior ideal of $S$ by Theorem 3.5. Let $A$ be any almost bi-quasi-interior ideal of $S$ such that $A \subseteq B$. By Lemma 1.1 and Theorem 3.5, we obtain that $C_{A}$ is a fuzzy almost bi-quasi-interior ideal of $S$ such that $C_{A} \subseteq C_{B}$. Since $C_{B}$ is minimal, it follows that $A=\operatorname{supp}\left(C_{A}\right)=\operatorname{supp}\left(C_{B}\right)=B$. Consequently, $B$ is a minimal almost bi-quasi-interior ideal of $S$.

The following corollary can be achieved by Theorem 3.5 and Theorem 3.6.

Corollary 3.9. Let $\mathrm{S}$ be a semigroup. Then $\mathrm{S}$ has no proper almost bi-quasi-interior ideals if and only if for every fuzzy almost bi-quasi-interior ideal $\mathrm{f}$ of $\mathrm{S}, \operatorname{supp}(\mathrm{f})=\mathrm{S}$.

Let $S$ be a semigroup. An almost bi-quasi-interior ideal $P$ of $S$ is called prime if for any almost bi-quasi-interior ideals $A$ and $B$ of $S$ such that $A B \subseteq P$ implies that $A \subseteq P$ or $B \subseteq P$. An almost bi-quasiinterior ideal $P$ of $S$ is called semiprime if for any almost bi-quasi-interior ideal $A$ of $S$ such that $A A \subseteq P$ implies that $A \subseteq P$. An almost bi-quasi-interior ideal $P$ of $S$ is called strongly prime if for any almost bi-quasi-interior ideals $A$ and $\mathrm{B}$ of $S$ such that $A B \cap B A \subseteq P$ implies that $A \subseteq \mathrm{P}$ or $\mathrm{B} \subseteq \mathrm{P}$.

Definition 3.10. A fuzzy almost bi-quasi-interior ideal $h$ of a semigroup $S$ is called a fuzzy prime almost bi-quasi-interior ideal of $S$ if for any two fuzzy almost bi-quasi-interior ideals $f$ and $g$ of $S, f \circ g \subseteq h$ implies that $f \subseteq h$ or $g \subseteq h$.

Definition 3.11. A fuzzy almost bi-quasi-interior ideal $h$ of a semigroup $S$ is called a fuzzy semiprime almost bi-quasi-interior ideal of $S$ if for any fuzzy almost bi-quasi-interior ideal $f$ of $S, f \circ f \subseteq h$ implies that $f \subseteq h$.

Definition 3.12. A fuzzy almost bi-quasi-interior ideal $h$ of a semigroup $S$ is called a fuzzy strongly prime almost bi-quasi-interior ideal of $S$ if for any two fuzzy almost bi-quasi-interior ideals $f$ and $g$ of $S,(f \circ g) \cap$ $(\mathrm{g} \circ \mathrm{f}) \subseteq \mathrm{h}$ implies that $\mathrm{f} \subseteq \mathrm{h}$ or $\mathrm{g} \subseteq \mathrm{h}$.

Obviously, every fuzzy strongly prime almost bi-quasi-interior ideal of a semigroup is a fuzzy prime almost bi-quasi-interior ideal, and every fuzzy prime almost bi-quasi-interior ideal of a semigroup is a fuzzy semiprime almost bi-quasi-interior ideal.

Finally, we will be studying the relationships between prime (resp., semiprime, strongly prime) almost bi-quasi-interior ideals and their fuzzification of semigroups.

Theorem 3.13. Let $\mathrm{P}$ be a nonempty subset of a semigroup $\mathrm{S}$. Then $\mathrm{P}$ is a prime almost bi-quasi-interior ideal of $\mathrm{S}$ if and only if $\mathrm{C}_{\mathrm{P}}$ is a fuzzy prime almost bi-quasi-interior ideal of $\mathrm{S}$.

Proof. Assume that $\mathrm{P}$ is a prime almost bi-quasi-interior ideal of $\mathrm{S}$. By Theorem $3.5, \mathrm{C}_{\mathrm{P}}$ is a fuzzy almost bi-quasi-interior ideal of $S$. Let $f$ and $g$ be fuzzy almost bi-quasi-interior ideals of $S$ such that $f \circ g \subseteq C_{P}$. Suppose that $f \nsubseteq C_{P}$ and $g \nsubseteq C_{P}$. Then, there exist $x, y \in S$ such that $f(x) \neq 0$ and $g(y) \neq 0$, while $C_{P}(x)=0$ and $C_{P}(y)=0$. This implies that $x \in \operatorname{supp}(f)$ and $y \in \operatorname{supp}(g)$, but $x, y \notin P$. It turns out that $\operatorname{supp}(\mathrm{f}) \nsubseteq \mathrm{P}$ and $\operatorname{supp}(\mathrm{g}) \nsubseteq \mathrm{P}$. Now, $\operatorname{supp}(\mathrm{f})$ and $\operatorname{supp}(\mathrm{g})$ are almost bi-quasi-interior ideals of $S$ by Theorem 3.6. Since $P$ is prime, $\operatorname{supp}(f) \operatorname{supp}(g) \nsubseteq P$. Then, there exists $t=a b$ for some $a \in \operatorname{supp}(f)$ 
and $\mathrm{b} \in \operatorname{supp}(\mathrm{g})$ such that $\mathrm{t} \notin \mathrm{P}$. Hence, $\mathrm{C}_{\mathrm{P}}(\mathrm{t})=0$ implies that $(\mathrm{f} \circ \mathrm{g})(\mathrm{t})=0$ since $f \circ \mathrm{g} \subseteq \mathrm{C}_{\mathrm{P}}$. Since $a \in \operatorname{supp}(f)$ and $b \in \operatorname{supp}(g)$, we get that $f(a) \neq 0$ and $g(b) \neq 0$. It follows that

$$
(f \circ g)(t)=\sup _{t=a b}[\min \{f(a), g(b)\}] \neq 0,
$$

which is a contradiction. This implies that $f \subseteq C_{P}$ or $g \subseteq C_{P}$. Therefore, $C_{P}$ is a fuzzy prime almost bi-quasi-interior ideal of $S$.

Conversely, assume that $C_{P}$ is a fuzzy prime almost bi-quasi-interior ideal of $S$. By Theorem 3.5, $P$ is an almost bi-quasi-interior ideal of $S$. Let $A$ and $B$ be any two almost bi-quasi-interior ideals of $S$ such that $A B \subseteq P$. Then, $C_{A}$ and $C_{B}$ are fuzzy almost bi-quasi-interior ideals of $S$ by Theorem 3.5. By Lemma 1.1 and Lemma 1.2, we have that $C_{A} \circ C_{B}=C_{A B} \subseteq C_{P}$. By the hypothesis, $C_{A} \subseteq C_{P}$ or $C_{B} \subseteq C_{P}$. This implies that $\mathrm{A} \subseteq \mathrm{P}$ or $\mathrm{B} \subseteq \mathrm{P}$. Consequently, $\mathrm{P}$ is a prime almost bi-quasi-interior ideal of $\mathrm{S}$.

The following theorem can be proved similar to Theorem 3.13.

Theorem 3.14. Let $\mathrm{P}$ be a nonempty subset of a semigroup $\mathrm{S}$. Then $\mathrm{P}$ is a semiprime almost bi-quasi-interior ideal of $\mathrm{S}$ if and only if $\mathrm{C}_{\mathrm{P}}$ is a fuzzy semiprime almost bi-quasi-interior ideal of $\mathrm{S}$.

Theorem 3.15. Let $\mathrm{P}$ be a nonempty subset of a semigroup $\mathrm{S}$. Then $\mathrm{P}$ is a strongly prime almost bi-quasi-interior ideal of $\mathrm{S}$ if and only if $\mathrm{C}_{\mathrm{P}}$ is a fuzzy strongly prime almost bi-quasi-interior ideal of $\mathrm{S}$.

Proof. Assume that $\mathrm{P}$ is a strongly prime almost bi-quasi-interior ideal of $\mathrm{S}$. By Theorem $3.5, \mathrm{C}_{\mathrm{P}}$ is a fuzzy almost bi-quasi-interior ideal of $S$. Let $f$ and $g$ be any two fuzzy almost bi-quasi-interior ideals of $S$ such that $(f \circ g) \cap(g \circ f) \subseteq C_{P}$. Suppose that $f \nsubseteq C_{P}$ and $g \nsubseteq C_{P}$. Then, there exist $x, y \in S$ such that $f(x) \neq 0$ and $g(y) \neq 0$, but $C_{P}(x)=0$ and $C_{P}(y)=0$. Also, $x \in \operatorname{supp}(f)$ and $y \in \operatorname{supp}(g)$ such that $x \notin P$ and $y \notin P$. We obtain that $\operatorname{supp}(f) \nsubseteq C_{P}$ and $\operatorname{supp}(g) \nsubseteq C_{P}$. By Theorem 3.6 and given assumption, we have that $[\operatorname{supp}(f) \operatorname{supp}(g)] \cap[\operatorname{supp}(g) \operatorname{supp}(f)] \not \subset$. Thus, there exists $t \in[\operatorname{supp}(f) \operatorname{supp}(g)] \cap[\operatorname{supp}(g) \operatorname{supp}(f)] \operatorname{such}$ that $t \notin P$. That is, $C_{P}(t)=0$, which implies that $[(f \circ g) \cap(g \circ f)](t)=0$ because $(f \circ g) \cap(g \circ f) \subseteq C_{P}$. Since $t \in \operatorname{supp}(f) \operatorname{supp}(g)$ and $t \in \operatorname{supp}(g) \operatorname{supp}(f)$, then $t=a_{1} b_{1}$ and $t=b_{2} a_{2}$ for some $a_{1}, a_{1} \in \operatorname{supp}(f)$ and for some $b_{1}, b_{2} \in \operatorname{supp}(g)$. This implies that

$$
(f \circ g)(t)=\sup _{t=a_{1} b_{1}}\left[\min \left\{f\left(a_{1}\right), g\left(b_{1}\right)\right\}\right] \neq 0, \text { and }(g \circ f)(t)=\sup _{t=b_{2} a_{2}}\left[\min \left\{g\left(b_{2}\right), f\left(a_{2}\right)\right\}\right] \neq 0 .
$$

This shows that $\min \{(f \circ g)(t),(g \circ f)(t)\} \neq 0$, that is, $[(f \circ g) \cap(g \circ f)](t) \neq 0$. This is a contradiction with the fact that $[(f \circ g) \cap(g \circ f)](t)=0$. Hence, $f \subseteq C_{P}$ or $g \subseteq C_{P}$. Therefore, $C_{P}$ is a fuzzy strongly prime almost bi-quasi-interior ideal of $S$.

Conversely, assume that $C_{P}$ is a fuzzy strongly prime almost bi-quasi-interior ideal of $S$. Then, $P$ is an almost bi-quasi-interior ideal of $S$ by Theorem 3.5. Let $A$ and $B$ be any two almost bi-quasi-interior ideals of $S$ such that $A B \cap B A \subseteq P$. Again by Theorem 3.5, $C_{A}$ and $C_{B}$ are also fuzzy almost bi-quasi-interior ideals of $S$. By Lemma 1.2, $C_{A B}=C_{A} \circ C_{B}$ and $C_{B A}=C_{B} \circ C_{A}$. Thus,

$$
\left(C_{A} \circ C_{B}\right) \cap\left(C_{B} \circ C_{A}\right)=C_{A B} \cap C_{B A}=C_{A B \cap B A} \subseteq C_{P} .
$$

Since $C_{P}$ is strongly prime, we get that $C_{A} \subseteq C_{P}$ or $C_{B} \subseteq C_{P}$ implies that $A \subseteq P$ or $B \subseteq P$. Consequently, $P$ is a strongly prime almost bi-quasi-interior ideal of $\mathrm{S}$.

\section{Conclusions}

In 2018, Rao [14] introduced the notion of bi-quasi-interior ideals as a generalization of quasi-ideals, bi-ideals, interior ideals, bi-interior ideals and bi-quasi ideals of semigroups. In this paper, as a further generalization of bi-quasi-interior ideals of semigroups, we introduced the concept of almost bi-quasiinterior ideals which is a generalization of bi-quasi-interior ideals of semigroups. By Corollary 2.5 , we conclude that the set of all almost bi-quasi-interior ideals of a semigroup $S$ forms a semigroup under 
the binary operation of union, but it is unable to form a semigroup under the binary of intersection as shown in Example 2.6. In Section 3, we have defined the notion of fuzzy almost bi-quasi-interior ideals of semigroups. For any semigroup $S$, we shown that the union of any two fuzzy almost bi-quasi-interior ideals of $S$ is also a fuzzy almost bi-quasi-interior ideal of $S$ in Corollary 3.3, while the intersection of two fuzzy almost bi-quasi-interior ideals of $S$ need not to be a fuzzy almost bi-quasi-interior ideal of $S$ in Example 3.4. Next, we characterized almost bi-quasi-interior ideals and fuzzy almost bi-quasiinterior ideals of semigroups in Theorem 3.5 and Theorem 3.6, respectively. Finally, we proved some relationship between almost bi-quasi-interior ideals and their fuzzification of semigroups were shown in Theorem 3.8, Theorem 3.13, Theorem 3.14 and Theorem 3.15. In our future study, we will consider the concepts of almost bi-quasi ideals and almost bi-interior ideals of semigroups and discuss the connections between these concepts and their fuzzifications in semigroups or various types of almost ideals and their fuzzifications in other algebraic structures.

\section{Acknowledgment}

This research project is financially supported by Mahasarakham University.

\section{References}

[1] S. Bogdanović, Semigroups in which some bi-ideal is a group, Univ. u Novom Sadu Zb. Rad. Prirod.-Mat. Fak. Ser. Mat., 11 (1981), 261-266. 1

[2] B. Davvaz, N. Firouzkouhi, Commutative rings derived from fuzzy hyperrings, Honam Math. J., 42 (2020), 219-234. 1

[3] O. Grošek, L. Satko, A new notion in the theory of semigroup, Semigroup Forum, 20 (1980), 233-240. 1

[4] L. Kamali Ardekani, B. Davvaz, On the number of fuzzy subgroups of dicyclic groups, Soft Comput., 24 (2020), 61836191. 1

[5] N. Kaopusek, T. Kaewnoi, R. Chinram, On almost interior ideals and weakly almost interior ideals of semigroups, J. Discrete Math. Sci. Cryptogr., 23 (2020), 773-778. 1

[6] F. M. Khan, N. H. Sarmin, H. U. Khan, A novel approach toward fuzzy generalized bi-ideals in ordered semigroups, Scient. World J., 2014 (2014), 9 pages. 2.2

[7] W. Krailoet, A. Simuen, R. Chinram, P. Petchkaew, A note on fuzzy almost interior ideals in semigroups, Int. J. Math. Comput. Sci., 16 (2021), 803-808. 1

[8] N. Kuroki, On fuzzy ideals and fuzzy bi-ideals in semigroups, Fuzzy Sets and Systems, 5 (1981), 203-215. 1

[9] P. Muangdoo, T. Chuta, W. Nakkhasen, Almost bi-hyperideals and their fuzzification of semihypergroups, J. Math. Comput. Sci., 11 (2021), 2755-2767. 1, 1.1, 1.2

[10] W. Nakkhasen, Intuitionistic fuzzy ideals of ternary near-rings, Int. J. Fuzzy Logic Intel. Syst., 20 (2020), 290-297. 1

[11] S. Nawaz, M. Gulistan, N. Kausar, Salahuddin, M. Munir, On the left and right almost hyperideals of LAsemihypergroups, Int. J. Fuzzy Logic Intel. Syst., 21 (2021), 86-92. 1

[12] P. Palakawong na Ayutthaya, B. Pibaljommee, Characterizations of ordered k-regularities on ordered semirings, Quasigroups Related Systems, 29 (2021), 107-121. 2.3

[13] P. M. Pu, Y. M. Liu, Fuzzy topology I. Neighborhood structure of a fuzzy point and Moore-Smith convergence, J. Math. Anal. Appl., 76 (1980), 571-599. 1

[14] M. M. K. Rao, A study of a generalization of bi-ideal, quasi ideal and interior ideal of semigroup, Math. Morav., 22 (2018), 103-115. 1, 1.3, 4

[15] Y. S. Rao, S. Kosari, Z. Shao, M. Akhoundi, S. Omidi, A study on A-I- $\Gamma$-hyperideals and ( $\mathrm{m}, \mathrm{n})$ - $\Gamma$-hyperfilters in ordered Г-semihypergroups, Discrete Dyn. Nat. Soc., 2021 (2021), 10 pages. 1

[16] A. Rosenfeld, Fuzzy groups, J. Math. Anal. Appl., 35 (1971), 512-517. 1

[17] A. Simuen, S. Abdullah, W. Yonthanthum, R. Chinram, Almost bi-Г-ideals and fuzzy almost bi- $\Gamma$-ideals of $\Gamma$-semigroups, Eur. J. Pure Appl. Math., 13 (2020), 620-630. 1

[18] A. Simuen, K. Wattanatripop, R. Chinram, Characterizing almost quasi-Г-ideals and fuzzy almost quasi- $\Gamma$-ideals of $\Gamma$-semigroups, Commun. Math. Appl., 11 (2020), 233-240.

[19] S. Suebsung, T. Kaewnoi, R. Chinram, A not on almost hyperideals in semihypergroups, Int. J. Math. Comput. Sci., 15 (2020), 127-133.

[20] S. Suebsung, K. Wattanatripop, R. Chinram, A-ideals and fuzzy A-ideals of ternary semigroups, Songklanakarin J. Sci. Tech., 41 (2019), 299-304.

[21] S. Suebsung, K. Wattanatripop, R. Chinram, On almost $(\mathrm{m}, \mathrm{n})$-ideals and fuzzy almost $(\mathrm{m}, \mathrm{n})$-ideals in semigroups, J. Taibah Univer. Sci., 13 (2019), 897-902.

[22] S. Suebsung, W. Yonthanthum, K. Hila, R. Chinram, On almost quasi-hyperideals in semihypergroups, J. Discrete Math. Sci. Cryptogr., 24 (2021), 235-244. 
[23] K. Wattanatripop, R. Chinram, T. Changphas, Fuzzy almost bi-ideals in semigroups, Int. J. Math. Comput. Sci., 13 (2018), 51-58. 1

[24] K. Wattanatripop, R. Chinram, T. Changphas, Quasi-A-ideals and fuzzy A-ideals in semigroups, J. Discrete Math. Sci. Cryptogr., 21 (2018), 1131-1138. 1

[25] L. A. Zadeh, Fuzzy set, Information and Control, 8 (1965), 338-353. 1 